\title{
Pengaruh Pengetahuan Kewirausahaan dan Kompetensi Kewirusahaan Guru Terhadap Intensi Berwirausaha Siswa SMK Nusantara Lubukpakam
}

\author{
Bambang Suseno', Amir Hamzah Nasution ${ }^{2}$ \\ 1 Universitas Deli Sumatera, Medan, Indonesia \\ 2 Development of Rural Economy Institute (DERINS), Kalimantan Barat, Indonesia \\ Corresponding Author:@ bambangkwh.1992@delisumatera.ac.i
}

ABSTRACT
Vocational High School graduates are the highest open unemployment of
Diploma and Bachelor graduates indicating they are unable to compete.
Therefore, it is necessary to have entrepreneurial skills that are able to open
up business and business opportunities for yourself. The purpose of this
study was to determine the effect of entrepreneurial knowledge and teacher
entrepreneurship competence on the entrepreneurial intentions of students
at SMK Nusantara Lubukpakam. The population is 62 students of class XII
accounting and institutional finance expertise programs and office
governance automation. And all are taken as samples. Data were collected
using a questionnaire. The data were then analyzed by quantitative
methods, namely multiple linear regression analysis. Based on the classical
assumption test, there is no classical assumption problem in the regression
model. Based on the results of the t-test, it was found that the variables of
entrepreneurial knowledge and teacher entrepreneurship competence
partially affect entrepreneurial intentions. The results of the F test show that
the two independent variables together have a significant effect on
Entrepreneurial Intentions. Based on the R2 test, it shows the contribution
of the entrepreneurial knowledge variable and the entrepreneurial
competence of teachers, amounting to $64.7 \%$ on the entrepreneurial
intention variable.

\section{PENDAHULUAN}

SMK merupakan pendidikan kejuruan menengah yang mempersiapkan peserta didik untuk dapat bekerja sesuai dengan kompetensinya masing-masing. Namun, pada saat ini lapangan pekerjaan yang tersedia tidak sebanding dengan jumlah lulusan SMK yang semakin meningkat. Berdasarkan Data Pusat Statistik yang dirilis Agustus 2020. Pengangguran terbuka pada agustus 2020 lulusan SD 3,61\%, SMP 6,46\%, SMA 9,86\%, SMK 13,55\%, Diploma 8,08\% dan 7,36\%. Dapat disimpulkan bahwa pengangguran tertinggi adalah lulusan SMK dengan mencapai 13,55\%. Hal ini mengindikasi bahwa lulusan SMK kalah bersaing dengan lulusan Diploma dan Sarjana. Oleh sebab itu maka lulusan SMK disiapkan memiliki skill wirausaha agar ketika mampu membuka peluang usaha dan mampu membuka lapangan pekerjaan untuk diri sendiri. 
Melalui pendekatan wirausaha mampu meberikan keterampilan keterampilan dan menciptkan peluang usaha. Wirasauha adalah orang yang berjiwa berani untuk mengambil resiko dalam mengambil peluang dalam membuka usaha (Kasmir, 2017). Untuk dapat berani mengambil peluang usaha maka dari itu siswa harus memiliki intensi berwirausaha. Intensi beriwausaha merupakan keyakinan dan niat dalam diri untuk berani membuka usaha. Dengan memiliki intensi seseorang akan memiliki kesiapan berwirausaha dan berkomitmen untuk mewujudkan keinginan tersebut. Intensi berwirausaha tidak dibawah dari lahir melainkan melaui proses pelatihan, pembelajaran dan faktor yang mempengaruhinya(Puspitaningtyas, 2017).

Intensi berwirausaha sering tidak memiliki oleh siswa SMK khususnya siswa SMK Nusantara Lubukpakam disebabkan pengetahuan kewirausahaan yang minim padahal sudah mendapakan dari proses belajar. Pengetahuan kewirausahaan merupakan hal yang dibutuhkan untuk menumbuhkan intensi bewirausaha. Dengan pengetahuan yang dimiliki seseorang akan lebih yakin atau niat membuka usaha. Pengetahuan kewirasahaan siswa didapatkan melalui pembelajaran kewirausahaan yang dapat menyiapkan siswa untuk siap memasuki dunia kerja dengan mempelajari karakteristik seseorang yang menjadi wirausaha ataupn sikap untuk bertahan dengan segala kemungkinan buruk di dunia kerja dengan ketatnya persaingan mendapatkan pekerjaan dan sebagai alternative untuk menemukan peluang usaha. Di SMK pembelajaran kewirausahaan yaitu mata pelajaran produk kreatif dan kewirausahaan, siswa mendapatkan 7 jam pelajaan dalam seminggu untuk kelas XI dan 8 jam pelajaran dalam seminggu untuk kelas XII. Dalam penerapan proses pembelajaran lebih ditekankan pada praktek. Namun didalam kenyataan dilapangan siswa lebih banyak mempelajari teori-teori sehingga kurang dalam praktek.

Faktor berikutnya guru mata pelajaran kewirausahaan harus memiliki kompetensi memadai dengan telah mempunyai pengalaman berbisnis, merasakan jatuh bangun saat merintis usaha dan mengembangkan usaha dan atau yang bersangkutan terlibat berperan aktif dalam kegiatan di dunia usaha dan industri pada posisi manajerial (Musnandar, 2014). Saat mengajarpun untuk dapat meningkatkan intensi bewirausaha guru harus memberi model pembelajaran yang inovatif (Suseno, 2018). Pembelajaran kewirausahaan yang terjadi saat ini yaitu 1) pola pembelajaran dominan pendidik belum memberikan kesempatan siswa berkembang, 2) hasil belajar masih sebatas ujian dan pembelajaran masih teoritis belum kepada praktis, 3) strategi, model dan pendekatan yang diterapkan masih ceramah dan penugasan, 4) buku pegangan sebagai penunjang pembelajaran kewirausahaan hampir tidak memiliki siswa, 5) hampir tidak pernah dan tidak ada menggunakan media pembelajaran seperti 
audio visual maupun yang interaktif (Hidayat, 2018). Sebab guru tidak memiliki pengalaman bisnis. Jika guru tidak mampu mengajarkan kewirausahaan dapat dapat memfasilitasi siswa dengan memberikan pelatihan kewirausahaan (Perwita, 2017). Pelatihan dengan mengundang narasumber seorang pengusaha kesekolah, memberikan tugas-tugas lapangan (wawancara kepada pengusaha sukses), memberikan tugas mandiri (membuat rencana usaha), melakukan magang di usaha-usaha kecil menengah untuk mempelajari persiapan dan pelaksanaan dalam berwirausaha serta melakukan tugas-tugas praktik kewirausahaan dilapangan bahkan memberikan praktik keterampilan kepada siswa. Selain itu juga dapat difasilitasi untuk mengenal tokoh-tokoh wirausahawan yang telah sukses dengan media ceramah, wawancara tokoh, mendatangkan narasumber, observasi video, menonton video, dan sebagainya (Sari,2018).

Urgensitas penelitian ini, dengan diketahuinya pengetahuan kewirusahaan dan kompetensi kewirausahaan guru terhadap intensi bewirausah siswa, maka dapat dijadikan perbaikan dan peningkatan mutu pembelajaran kewirausahaan dalam meningkatkan intensi berwirausaha siswa. Berdasarkan permasalahan yang telah diuraikan, penulis tertarik untuk meneliti dengan judul "Pengaruh Pengetahuan Kewirausahaan dan Kompetensi Kewirusahaan Guru terhadap Intensi Berwirausaha Siswa SMK Nusantara Lubukpakam".

\section{METODE PENELITIAN}

Pada penelitian ini peniliti menggunakan pendekatan assosiatif. Pendekatan asosiatif adalah penelitian yang bertujan untuk mengetahui hubungan dua variabel atau lebih dengan perhitungaan angka-angka kemudian digunakan untuk pengambilan keputusan dalam memecahkan masalah dan data yang diperoleh dianalisis dengan menggunakan teori yang berlaku secara umum (Sugiyono 2016). Populasi dalam penelitian ini adalah siswa kelas XII SMK Nusantara Lubukpakam pada program keahlian Akuntansi Keuangan dan Lembaga dan Otomatisasi Tata Kelola Perkantoran. Sampel penelitian adalah kelas XII SMK Nusantara Lubukpakam pada program keahlian Akuntansi Keuangan dan Lembaga dan Otomatisasi Tata Kelola Perkantoran. Teknik Pengambil sampel menggunakan teknik total sampling yaitu semua populasi dijadikan sampel.

Metode pengumpulan pada penelitian ini menggunakan kuesioner atau angket yang disebar kepada siswa kelas XII SMK Nusantara Lubukpakam pada program keahlian Akuntansi Keuangan dan Lembaga dan Otomatisasi Tata Kelola Perkantoran Tahun Ajaran 2020/2021. Teknik dalam analisi data 
penelitian ini yaitu uji asumsi klasik meliputi uji normalitas, uji multikolinearitas, dan uji linearitas. Dalam analisi data menggunakan regresi linear berganda.

\section{HASIL DAN PEMBAHASAN}

\section{Hasil Penelitian}

Hasil pengujian asumsi klasik yang dilakukan dengan uji nomalitas dapat dilihat pada gambar 1 .

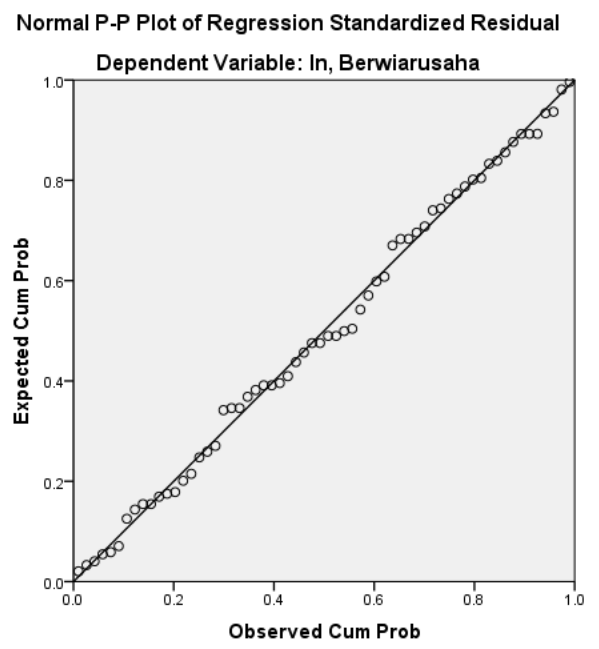

Gambar 1. Uji Normalitas P-Plot

Berdasarkan Gambar 1 bahwa model regresi telah memenuhi asumsi yang telah dikemukakan, hasil nilai pengetahuan kewirausahaan telah terdistribusi normal karena masing-masing memiliki nilai problabiliti lebih dari 0,05. Nilai variabel yang memenuhi standar yang ditetapkan pada dari Asym.sig. (2-tailed) =0,090. Dari nilai tersebut dapat disimpulkan bahwa nilai Asym.sig (2-tailed) lebih besar dari 0,05 yang berarti variabel telah terdistribusi secara normal.

Pengujian Multikolinearitas dilakukan untuk melihat ada korelasi antar variabel independen. Penelitian ini dengan regresi linear berganda antar variabel independen tidak boleh terjadi saling berkorelasi.

Tabel 1 Hasil Pengujian Multikolinearitas

\begin{tabular}{|ll|r|r|r|}
\hline \multirow{2}{*}{ Model } & & \multicolumn{3}{|c|}{ Collinearity Statistics } \\
\cline { 3 - 5 } & (Constant) & $\mathrm{B}$ & Tolerance & \multicolumn{1}{c|}{ VIF } \\
& Peng. Kewirausahaan & 1.722 & & \\
& Kom. Kewirusaha Guu & .283 & .902 & 1.109 \\
& & .766 & .902 & 1.109 \\
\hline
\end{tabular}

a. Dependent Variable: Intensi, Berwiarusaha 
Hasil menunjukan semua varibel independent masing-masing memiliki nilai VIF berada $<10$ dan tolerance $>0,10$. Maka disimpulkan bahwa penelitian tidak terjadi multikolineariaritas.

Pengujian linearitas dilakukan untuk mengetahui bahwa variabel bebas (X) dan variabel terikat $(\mathrm{Y})$ mempunyai pengaruh yang linear atau tidak linear.

Tabel 2 Hasil Pengujian Linearitas

\begin{tabular}{|c|c|c|}
\hline Model & $\begin{array}{c}\text { Nilai Sig. Deviation } \\
\text { from linearity }\end{array}$ & Ket. \\
\hline $\begin{array}{c}\text { Pengetahuan Kewirausahaan * } \\
\text { Intensi Berwirausaha }\end{array}$ & 0,408 & Linear \\
\hline $\begin{array}{c}\text { Kompetensi Kewirusahaan Guru * } \\
\text { Intensi Berwirausaha }\end{array}$ & 0,647 & Linear \\
\hline
\end{tabular}

Hasil menunjukkan bahwa semua variabel memiliki sig. Deviation from linearity $>0,05$. Maka dapat disimpulkan terdapat pengaruh yang linear antara variabel independent terhadap intensi berwirausaha.

\section{Pembahasan}

\section{Pengaruh Pengetahuan Kewirusahaan Terhadap Intensi Berwirausaha}

Berdasarkan hasil penelitian didapat pengaruh pengetahuan kewirausahaan terhadap intensi berwirausaha siswa SMK Nusantara Lubukpakam dengan $\mathrm{T}_{\text {hitung }}>\mathrm{T}_{\text {tabel }}=3,266>1,66$. Hal ini membuktikan terdapat pengaruh pengetahuan kewirausahaan terhadap intensi berwirausaha siswa SMK Nusantara Lubukpakam. Hasil jawaban quesioner pengetahuan kewirusahaan siswa SMK Nusantara sudah cukup baik dan belum tertarik untuk berwirausaha. Untuk itu perlu adanya inovasi dalam proses pembelajaran kewirausahaan.

Siswa yang memiliki pengetahuan kewirausahaan yang baik akan lebih yakin dalam berwirausaha. Siswa dapat memiliki pengetahuan kewirausahan melaui proses pembelajaran kewirusahaan sekolah yang berkualitas dengan menerapakap praktek langsung untuk melakukan usaha. Perlunya pengetahuan kewirausahaan untuk menumbuhkan niat atau intensi untuk berwirausaha, dengan adanya praktek kewirausahaan akan meningkatkan intensi dalam berwirausaha. (Pangiuk \& Ambok, 2017)

Pengetahuan kewirausahaan adalah suatu keseluruhan yang telah diketahui tentang informasi, diolah kedalam proses ranah kognitif menjadi ingatan dan pemahaman cara berusaha agar menimbulkan keberanian untuk mengambil resiko secara rasional dan logis dalam merintis suatu usaha. (Triane, 2019). Dalam proses kewirausahaan dituntut untuk mau mengambil resiko dari segala perhitungan agar dapat mengatasi rintangan untuk mencapai 
Journal Economy And Currency Study (JECS)

Volume 4, Issue 1, January 2022

Page 69-76

kesuksesan yang diharapkan. Karena pada umumnya wirausahawan menggunakan kecerdikannya untuk memanfaatkan sumberdaya yang terbatas (Perwita, 2017).

Dengan pengetahuan kewirausahaan yang telah diberikan dalam mata pelajaran produk kreatif dan kewirausahaan akan menimbulkan adanya perubahan pola pikir siswa dalam memandang suatu karir dan masa depan yang nantinya siswa akan mulai menyadari bahwa karir dalam berwirausaha atau menjadi pembisnis sangat prospek dan menantang. (Handayani, 2016)

Pengaruh Kompetensi Kewirausahaan Guru Terhadap Intensi Berwirausaha.

Hasil temuan yang kedua bahwa pengaruh kompetensi kewirausahaan guru terhadap intensi berwirausaha siswa SMK Nusantara Lubukpakam dengan $\mathrm{T}_{\text {hitung }}>\mathrm{T}_{\text {tabel }}=8,342>1,66$. Hal ini membuktikan terdapat pengaruh komptensi kewirsuahaan siswa terhadap intensi berwirausaha siswa SMK Nusantara Lubukpakam.

Guru yang mengajar kewirausahaan harus memiliki komptensi dibidang kewirausaha sehingga saat mengajar guru dapat membangkitan dan momotivasi siswa untun memiliki intensi berwirausha. Saat guru memiliki pengalaman bisnis akan mudah menularkan ke siswa, dengan pengalaman yang dimiliki menjelaskan permasalahan-permasalahan dalam usaha tidak hanya cerita fiktif atau hanya sekedar teori. Guru juga dapat memfasilitasi siswa untuk melalui magang di UMKM, obeservasi, memberikan tugas projek usaha dan mengeli tokoh-tokoh wirusahawan yang telah sukses menggunakan media audiovisual atau wawancara seoarng pengusaha sukses.

Pengaruh Pengetahuan kewirausahaan dan Kompetensi Kewirausahaan Guru Terhadap Intensi Berwirausaha.

Hasil temuan yang ketiga bahwa pengetahuan kewirausahaan dan kompetensi kewirusahaan berpengaruh terhadap intensi bewirausaha siswa SMK Nusantara Lubukpakam yang menyatakan $F_{\text {hitung }}=53,973>\mathrm{Ft}_{\text {abel }}=3,15$ dengan nilai problabilitas yang siginifikan $0,000<0,05$. Hasil uji determinasi bahwa sebesar 0,647 atau 64,7\% yang artinya 64,7\% pengetahuan kewirausahaan dan komptensi kewirausahaan mampu meningkatkan intensi berwirausaha siswa SMK Nusantara selebihnya sebesar 36,3\% dipengaruhi faktor lain diluar penelitian. 


\section{KESIMPULAN}

Berdasarkan pembahasan diatas dapatlah disimpulkan bahwa: 1) Pengetahuan kewirausahaan berpengaruh terhadap intensi berwirausaha. 2) Kompetensi kewirausahaan guru berpengaruh terhadap intensi berwirausaha. 3) Pengetahuan kewirausahaan dan kompetensi kewirausahaan guru berpengaruh terhadap intensi berwirausaha. Hal ini menunjukan bahwa pengetahuan kewirausahaan dan kompetensi kewirusahaan guru dapat mendorong dalam meningkatkan intensi berwirausaha.

\section{REFERENCES}

Handayani, TriI (2016) Evaluasi Tentang Pengetahuan Kewirausahaan Dalam Meningkatkan Intensi Berwirausaha (Studi Pada Mahasiswa Politeknik Negeri Bengkalis) Jurnal Inovasi dan Bisnis, Vol. 4, No. 2, Desember 2016, hlm. 91-98 https://media.neliti.com/media/publications/236267evaluasi-tentang-pengetahuan-kewirausaha-32e776a3.pdf

Hendra, Hidayat Dkk (2018) Pembelajaran Kewirausahaan Dengan Berbasis Produksi Sebagai Altenatif Mempersiapkan Lulusan Perguruan Tinggi Yang Berkualitas. Prosiding Seminar Nasional Pakar 2018 Buku II https://www.trijurnal.lemlit.trisakti.ac.id/pakar/article/view/2709/2339

Kasmir.2017. Kewirausahaan (edisi revisi). Jakarta: Rajagrafindo Persada

Musnandar, A. 2014. opini-kriteria-dosen-kewirausahaan-yang-tepat. Retrieved Desember 30, 2021, from http://www.umm.ac.id: http://www.umm.ac.id/en/opini/kriteria-dosen-kewirausahaan-yangtepat.html

Pangiuk \&Ambok (2017) Pengaruh Pengetahuan Kewirausahaan, Kecerdasan Adversitas, Dukungan Keluarga Dan Norma Subyektif Terhadap Intensi Berwirausaha Mahasiswa Fakultas Ekonomi Dan Bisnis Islam Uin Sts Jambi Tahun Vol2,No.2 Januari $2017 \quad$ https://EJournal.Lp2m.Uinjambi.Ac.Id/Ojp/Index.Php/Ijieb/Article/View / 240

Perwita, Dyah (2017) Upaya Guru Sekolah Menengah Kejuruan (Smk) Dalam Meningkatkan Minat Berwirausaha Siswa. Vol.5. No.2 (2017) 9-14 p-ISSN 2337-4721 DOI: http:/ / dx.doi.org/10.24127/ja.v5i2.1209

Puspitaningtyas, Zahra (2017) Pengaruh Efikasi Diri dan Pengetahuan Manajemen Keuangan Bisnis Terhadap Intensi Berwirausaha. Jurnal Wira Ekonomi $\begin{array}{llllll}\text { Microskill } & \text { Volume } & 7 & \text { No. } & 02 & \text { Oktober } \\ 2017\end{array}$ https:/ / www.mikroskil.ac.id/ejurnal/index.php/jwem/article/view/47 4

Sari, Indah Purna (2018) Implementasi Model Addie Dan Kompetensi Kewirausahaan 
Dosen Terhadap Motivasi Wirausaha Mahasiswa. Jurnal Ekonomi Pendidikan dan Kewirausahaan. Vol. 6 No. 1 DOI: https:/ / doi.org/10.26740/jepk.v6n1.p8394

Sugiono. 2016. Metode Penelitian Kuantitatif, Kualitatif Dan R\&D. Bandung: Alfabeta Suseno, Bambang (2018) The Influence Of School Environment, Teachers Attitude And Personality On Students Motivation At SMK Nusantara Lubuk Pakam With Students Self-Concept As The Intervening Variable Volume 7 - Issue 6, June 2018 Edition https: / / www.ijstr.org/ paper-references.php?ref=IJSTR-051819085

Triane, Ulfa (2019) Implikasi Pengetahuan Kewirausahaan dan Kreativitas Terhadap Intensi Berwirausaha Siswa Kelas XII SMKN 1 Padang Panjang Tahun Ajaran 2019/2020 Jurnal EcoGen Volume 2, Nomor 4, 5 Desember 2019 DOI:http:/ /dx.doi.org/10.24036/jmpe.v2i4.7852 